\title{
LOS ESPACIOS RURALES ESPAÑOLES: ¿TERRITORIOS DONDE SE PRODUCE Y CONSUME TURISMO O DESTINOS SOSTENIBLES EN ENTORNOS COMPETITIVOS? EL CASO DEL NORDESTE SEGOVIANO
}

\author{
Fernando Martín Gil \\ Departamento de Geografía. Universidad Autónoma de Madrid \\ f.martin@uam.es \\ Iris Martín Hernanz \\ Universidad Estatal Amazónica de Ecuador \\ irs20@hotmail.com
}

\section{RESUMEN}

En España abundan territorios que ofrecen un modelo genérico de turismo rural. El crecimiento de la oferta, su expansión a todos los espacios rurales y cambios globales en un mercado post-fordista generan una creciente competencia que cuestiona la sostenibilidad económica de la actividad. El artículo aborda el escenario que plantea a las áreas rurales españolas la necesidad de evolucionar desde espacios donde se produce y consume turismo a destinos competitivos. Mediante el estudio de caso de la comarca del Nordeste segoviano se extraen conclusiones extrapolables al conjunto del mundo rural español.

Palabras clave: post-fordismo, turismo rural, destinos turísticos, competencia, sostenibilidad, nordeste segoviano.

\begin{abstract}
In Spain abound territories that offer a generic model of rural tourism. The supply growth, its expansion to all rural areas and global changes in a post-Fordist market generate increased
\end{abstract}

Fecha de recepción: marzo 2012.

Fecha de aceptación: febrero 2013. 
competition that challenges the sustainability of the activity. The article discusses the scenario posed to Spanish rural destinations the need to move from areas where tourism is produced and consumed to competitive tourism destinations. By studying the case of the Northeast region Segovia draws conclusions extrapolated to the whole Spanish rural areas.

Key words: Post-Fordism, rural tourism, tourism destinations, competition, sustainability, Segovia northeast region.

\section{INTRODUCCIÓN}

Al igual que ha sucedido en otros países europeos el turismo en España se ha extendido a todos los territorios, incluidas las áreas rurales remotas. Como también sucede en el continente, ningún espacio rural español queda excluido de este tipo de procesos y de las dinámicas de apropiación del territorio por parte del turismo (Knafou, 2006: 26-27). Por tanto, el conocimiento de los problemas que pueda atravesar o generar la actividad en España constituye una cuestión relevante desde la perspectiva sectorial, para el desarrollo rural y el equilibrio territorial.

Un somero análisis de la bibliografía sobre turismo rural en España revela cómo los principales temas que han captado la atención de los investigadores en nuestro país son el crecimiento de la oferta, las diferencias regionales en materia normativa reguladora, las experiencias de puesta en valor del patrimonio, los impactos territoriales de la actividad, las consecuencias de las políticas públicas de fomento en su despegue y desarrollo, las características de la demanda y el papel de la mujer como empresaria o trabajadora (Varela y Martin 2011; Cómez y Rico, 2005; Martin, 1995; Cánoves et al., 2005). También evidencia que apenas se ha tratado de discernir sobre un problema fundamental para la sostenibilidad económica de la actividad: hasta qué punto los territorios han logrado transformarse en destinos turísticos articulados y competitivos trascendiendo el estadio inicial de espacios en los que se produce y consume turismo.

El principal objetivo de este artículo es paliar en parte este déficit y proponer esta cuestión como línea de investigación de futuro. Para ello se aborda, en primer lugar, un problema central para la sostenibilidad del turismo rural en un escenario de aumento de la competencia: la importancia que tiene la transformación de los territorios en destinos turísticos donde los agentes cooperen generando sinergias favorecedoras de la diferenciación, la innovación, la especialización y la creación de productos con elevado valor añadido. A continuación se analiza la cuestión en la comarca del Nordeste Segoviano con la intención de extraer conclusiones de interés para el futuro del turismo rural español. Los resultados han sido obtenidos en diferentes proyectos de investigación realizados desde 1989. Una Tesis Doctoral titulada «Mercado de Trabajo en áreas rurales. Un enfoque integrador» (1993), un estudio sectorial sobre turismo activo y de naturaleza en el «Parque Natural de las Hoces del río Duratón» (2000) y el proyecto «Puesta en valor sostenible de las estructuras territoriales para el turismo y el ocio de las sociedades urbanas. Un nuevo modo de articulación urbano-rural» (grupo de investigación «TERRITUR», UAM, 2004-2007). A lo largo de los 20 años transcurridos entre el primero y el último de estas investigaciones se realizaron un total de 478 
encuestas a visitantes y residentes y 56 entrevistas en profundidad a visitantes y operadores turísticos locales. Los agentes locales (empresarios, trabajadores y residentes) fueron entrevistados en dos períodos, el comprendido entre 1991-1993 y entre 2004-2007, con el objetivo de obtener información sobre sus percepciones en cada uno de aquellos momentos. Parte de las conclusiones de los proyectos junto con información obtenida de registros administrativos de urbanismo y patrimonio han servido de base para elaborar este trabajo.

\section{EL TURISMO RURAL ESPAÑOL: UNA ACTIVIDAD MADURA SOMETIDA A CRECIENTE COMPETENCIA}

En los últimos veinticinco años hemos asistimos a una rápida expansión del turismo rural en España. En este tiempo se han creado numerosas infraestructuras de acogida, se ha puesto en valor cuantioso patrimonio territorial y los servicios turísticos han crecido, diversificado y difundido a todos los espacios rurales. En apenas dos décadas un modelo de turismo rural tradicional, sin apenas infraestructuras comerciales de acogida y basado en el retorno veraniego de inmigrantes, ha dado paso a otro de carácter comercial consumido por una demanda heterogénea y exigente, presente en todos los territorios y sometido a una competencia en aumento. Esta rápida transición ha generado múltiples impactos económicos, socioculturales y territoriales que postulan al turismo como protagonista central del desarrollo rural. Entre otros la revalorización del patrimonio natural y cultural local en las sociedades receptoras, su conservación, rehabilitación y puesta en valor, la generación de nuevo tejido productivo y empleo y el incremento de la calidad de vida de la población local como resultado de la creación de equipamientos y servicios diseñados para el turista y también utilizados por los residentes.

Conforme el turismo rural ha crecido se ha producido un proceso reiterado de copia y réplica, en múltiples ámbitos rurales y en muy breve plazo de tiempo ${ }^{1}$, de los nuevos productos. En esta dinámica, que explica en buena medida la homogeneidad de la oferta en los diferentes territorios, han tenido una incidencia clave las políticas públicas de fomento. Especialmente las Iniciativas y Programas Comunitarios de Desarrollo Rural LEADER y PRODER $^{2}$, los Planes de Dinamización Turística impulsados desde la Administración General del Estado (Fuentes, 1999; Monserin, 2008; Almeida et al., 2005) y propuestas similares impulsadas por comunidades autónomas como los Planes de Turismo Sostenible andaluces.

1 Hace veinte años apenas encontrábamos productos de turismo minero en España. Sin embargo, tras las primeras puestas en valor en la última década del siglo XX en Rio Tinto y Asturias, hoy podemos visitar en España en torno a treinta minas o complejos mineros y se está trabajando en la actualidad en un número parecido de proyectos (Jordá et al., 2010). Otro ejemplo lo encontramos en el enoturismo: al enfoque dominante hace apenas veinte años de visita a unas pocas bodegas del país hoy se contrapone una proliferación de propuestas, ofertadas en buena parte de las sesenta y siete denominaciones de origen españolas, que incluyen rutas tematizadas, spa, visitas a viñedos, curso de cata y actividades como la participación en la vendimia.

2 Puede realizarse una primera aproximación a la cuestión consultando los trabajos de Jolín (2002), Pérez y López (2005), Gordo (2011) y Foronda (2006). Conviene señalar al respecto uno de los principales objetivos de LEADER y PRODER: la difusión de experiencias e innovaciones. De hecho, las bases de las convocatorias fomentaban el desarrollo de proyectos de cooperación para difundir experiencias, es decir, para su réplica adaptada en diferentes territorios. 
Junto a los efectos de las políticas públicas y del desarrollo económico general otros factores, asociados a cambios estructurales globales, explican la expansión del turismo rural en España y la necesidad de avanzar en la creación de propuestas diferenciables. La evolución del perfil de un turista convencional hacia otro con mayor experiencia viajera, más y mejor informado, con nuevas motivaciones, necesidades y demandas, favorece el crecimiento y la diversificación de la oferta e incentiva a empresarios y destinos a invertir en propuestas donde calidad y adaptación al mercado son factores fundamentales de la competitividad. Además, empuja a empresas y destinos a diseñar productos innovadores y especializados con el objetivo de captar nuevos segmentos de mercado (Ioannides, 1997), cuestión que explica la proliferación de propuestas dirigidas a nichos de mercado como el orniturismo, el geoturismo, el turismo de cuevas, el enoturismo o el micoturismo (López, 2008; López-Guzmán y Sánchez, 2008; Rodríguez, López-Guzmán Guzmán y Sánchez, 2010; Gonzalez-Ríos y Ramírez, 2007; Jordá et al., 2010; Ginés, 2007).

La evolución del perfil de un turista tradicional a otro postmoderno caracterizado por su hipermovilidad (Urry, 2002), habituado a viajar, exigente y que aspira a consumir «experiencias auténticas y únicas» estimula a empresas y destinos a invertir esfuerzos constantes en el diseño de nuevos productos diferenciables, cada vez más sofisticados, especializados y complejos en su planificación y gestión. También a desarrollar costosas campañas de promoción para llegar al mercado. Ahora bien, en un mundo rural donde predominan microoperadores con escasa capacidad financiera estas tareas estratégicas sólo pueden llevarse a cabo con eficiencia mediante la coordinación de esfuerzos entre agentes, trabajo en red y uso generalizado de nuevas tecnologías de la información. Todas estas cuestiones, que definen en buena medida a los destinos turísticos competitivos, independientemente de su naturaleza (Brito, 2009), aún no están resueltas en la mayor parte de los espacios rurales españoles.

La crisis del modelo de producción impulsa transformaciones hacia planteamientos postfordistas, más flexibles y capaces de responder con rapidez a los cambios de la demanda, y genera nuevas oportunidades para las pequeñas empresas. Sin embargo, la lógica postfordista no está exenta de tensiones porque los procesos, además de extenderse a todos los territorios, incluyen nuevas propuestas adaptadas a las dinámicas de segmentación de la demanda junto a otras tradicionales heredadas del modelo fordista (Donaire, 1998:2-4). En este contexto, donde cohabitan viejas y nuevas propuestas, la microempresa turística, forma de organización productiva más extendida en las áreas rurales españolas, cuenta con ventajas comparativas por su capacidad para adaptarse a los cambios.

Hace veinticinco años en nuestras zonas rurales apenas encontrábamos alojamientos, restaurantes, empresas de servicios deportivos, culturales o de naturaleza. Entonces, cualquier actividad, por ejemplo un alojamiento rural, podía funcionar con éxito con independencia de su calidad, singularidad o el atractivo de sus servicios porque actuaba, de hecho, en un mercado emergente sin apenas competencia ${ }^{3}$. Hoy, por el contrario, encontramos oferta en todas las comarcas rurales de forma que el mismo alojamiento actúa en un entorno muy

3 La creación de alojamientos rurales en España es un proceso reciente en términos históricos. En 1990 sólo cuatro comunidades Autónomas (Aragón, Cantabria, Cataluña y País Vasco) habían legislado en la materia y su número estimado se situaba en torno a trescientos (Martin, 1995: 149). A estos habría que sumar un número parecido de establecimientos no reglados pero similares que operaban en Andalucía, Asturias y otras comunidades autónomas. En 2011, el número de establecimientos supera los 15.000. 
competitivo donde existen al menos 15.000 posibilidades de elección para el consumidor (Tabla 1). Esta nueva situación refleja una fuerte competencia, que tiende a aumentar, y remite a considerar al turismo rural español como un fenómeno maduro o próximo a esta situación. En estas circunstancias la supervivencia a medio y largo plazo obliga a las empresas a realizar mejoras permanentes de su oferta con el fin de mantener su capacidad de atracción. Y a los territorios, como señala Butler (1980) en sus planteamientos sobre el ciclo de vida de los destinos turísticos, a tomar decisiones para adaptarse a la situación, innovar y evitar el estancamiento o declive.

Una de las debilidades del turismo rural español es el predominio de territorios con ofertas que responden a un «modelo genérico» de turismo rural basado en tópicos como la calidad del paisaje, escenarios para la relajación y el descanso, el tipismo y la gastronomía tradicionales (Varela y Martin, op. cit.). En un escenario de competencia creciente las actividades turísticas en estos territorios se enfrentan a importantes problemas de sostenibilidad económica, cuestión que ya anticipa las estadísticas oficiales.

Tabla 1

EVOLUCIÓN DE LA OFERTA DE ALOJAMIENTO RURAL EN ESPAÑA (2001-2011)

\begin{tabular}{|c|c|c|c|c|c|}
\hline \multirow{2}{*}{ Año } & \multirow{2}{*}{$\begin{array}{c}\mathbf{N}^{\mathbf{0}} \mathbf{d e} \\
\text { alojamientos }\end{array}$} & \multirow{2}{*}{$\begin{array}{c}\mathbf{N}^{\mathbf{0}} \mathbf{d e} \\
\text { plazas }\end{array}$} & \multicolumn{2}{|c|}{ Incremento anual } & \multirow{2}{*}{$\begin{array}{c}\text { Plazas por } \\
\text { establecimiento }\end{array}$} \\
\cline { 4 - 5 } & & & Establecimientos & Plazas & \\
\hline 2001 & 5.496 & 42.925 & sin datos & sin datos & 7,81 \\
\hline 2002 & 6.003 & 51.010 & 9,2 & 18,8 & 8,50 \\
\hline 2003 & 6.973 & 59.884 & 16,2 & 17,4 & 8,59 \\
\hline 2004 & 8.233 & 71.488 & 18,1 & 19,4 & 8,68 \\
\hline 2005 & 9.629 & 83.916 & 17,0 & 17,4 & 8,71 \\
\hline 2006 & 10.830 & 95.906 & 12,5 & 14,3 & 8,88 \\
\hline 2007 & 11.532 & 103.313 & 6,5 & 7,7 & 8,96 \\
\hline 2008 & 12.794 & 114.766 & 10,9 & 11,1 & 8,97 \\
\hline 2009 & 13.886 & 126.222 & 8,5 & 10,0 & 9,09 \\
\hline 2010 & 14.320 & 130.882 & 3,1 & 3,7 & 9,14 \\
\hline 2011 & 15.037 & 137.727 & 5,0 & 5,2 & 9,16 \\
\hline
\end{tabular}

Fuente: Elaboración propia a partir de datos de la Encuesta de Alojamientos Rurales, Instituto Nacional de Estadística.

Desde finales de los años ochenta del siglo pasado hasta la actualidad no ha dejado de crecer el número de usuarios, de alojamientos, de restaurantes y la capacidad de ambos tipos de infraestructuras. Sin embargo, la evolución del número de usuarios por alojamiento descendió de manera muy notable entre 2001 (220,3) y 2011 (180,5), tendencia que también registró, pero de forma más acusada, la ratio entre número de usuarios y de plazas $(28,2$ y 19,7). Ambas tendencias fueron resultado de un mayor crecimiento de la oferta respecto 
a la demanda. A la vez que esto sucedía los alojamientos rurales mostraban una excesiva dependencia del turista nacional, una muy reducida capacidad para captar mercados internacionales (tabla 2) y una baja ocupación (tabla 3). La combinación de todo ello junto al mantenimiento del ritmo positivo de creación de infraestructuras, una capacidad de acogida por establecimiento cada vez mayor (tabla 1) y al estancamiento del número de usuarios augura un descenso de la rentabilidad de las inversiones y un duro incremento de la competencia. Es decir, problemas para la sostenibilidad de la actividad en empresas y territorios que no logren adaptarse a la situación.

Tabla 2

EVOLUCIÓN DEL NÚMERO DE USUARIOS DE ALOJAMIENTOS RURALES EN ESPAÑA (2001-2011)

\begin{tabular}{|c|c|c|c|c|}
\hline Año & Número total & $\begin{array}{c}\text { Con residencia } \\
\text { en España }\end{array}$ & $\begin{array}{c}\text { Con residencia fuera } \\
\text { de España }\end{array}$ & $\begin{array}{c}\text { Residentes en España } \\
\text { sobre el total }\end{array}$ \\
\hline 2001 & 1.210 .891 & 1.086 .766 & 124.125 & 89,7 \\
\hline 2002 & 1.370 .369 & 1.229 .852 & 140.517 & 89,7 \\
\hline 2003 & 1.467 .539 & 1.322 .704 & 144.835 & 90,1 \\
\hline 2004 & 1.754 .360 & 1.588 .289 & 166.071 & 90,5 \\
\hline 2005 & 1.982 .902 & 1.770 .403 & 212.499 & 89,3 \\
\hline 2006 & 2.425 .429 & 2.180 .235 & 245.194 & 89,9 \\
\hline 2007 & 2.645 .237 & 2.382 .411 & 262.826 & 90,1 \\
\hline 2008 & 2.623 .351 & 2.360 .968 & 262.383 & 90,0 \\
\hline 2009 & 2.714 .265 & 2.448 .873 & 265.392 & 90,2 \\
\hline 2010 & 2.647 .370 & 2.360 .605 & 286.765 & 89,2 \\
\hline 2011 & 2.714 .066 & 2.378 .653 & 335.413 & 85,9 \\
\hline
\end{tabular}

Fuente: Elaboración propia a partir de datos de la Encuesta de Alojamientos Rurales, Instituto Nacional de Estadística.

En un entorno de competencia creciente entre destinos, productos y empresas, demanda exigente, informada y con experiencia viajera, capacidad reducida para captar mercados externos, crecimiento de la oferta, gasto turístico estancado y a distribuir entre un mayor número de destinos y operadores, la sostenibilidad económica de la actividad dependerá cada vez más de la capacidad de atracción y fidelización de los territorios. Esta, a su vez, de su destreza para elaborar productos especializados, diferenciados, integrados por diferentes recursos, con elevado valor añadido e identificables por el mercado. En definitiva, el futuro del turismo de los espacios rurales españoles dependerá de la eficacia de sus agentes públicos y privados para actuar de forma coordinada, crear redes de colaboración, clústeres turísticos y partenariados generadores de sinergias (Cánoves, et. al. op. cit.:3) que faciliten la creación de ofertas de calidad y atractivas. Es decir, de su capacidad para transformar territorios en destinos turísticos articulados y con imagen reconocida.

Aunque en España predominan los territorios rurales que sólo pueden definirse como destinos porque en ellos se produce y consume turismo, algunos territorios han logrado arti- 
cular su oferta y generar destinos especializados mediante el aprovechamiento de patrimonio con potente capacidad de atracción como infraestructuras mineras, yacimientos paleontológicos o arqueológicos, arquitectura popular, espacios naturales protegidos, vías abandonadas de ferrocarril, cursos de agua o geología monumental. Estos serían los casos, entre otros, del «Maestrazgo» turolense, la «Ribera Sacra» gallega, el «Valle del Cidacos» (Rioja), la «Sierra de Guara» (Huesca) o «La Selva» (Gerona). Todos ellos muestran características comunes como disponer de estrategias planificadas consensuadas de desarrollo turístico, contar con productos que integran diferentes recursos y ofertas especializadas, haber consolidado imágenes diferenciadas en el mercado, puesto en funcionamiento redes de colaboración entre agentes y estructuras operativas de gestión del desarrollo turístico ${ }^{4}$.

Tabla 3

EVOLUCIÓN DE LA OCUPACIÓN DE LOS ALOJAMIENTOS RURALES EN ESPAÑA (2001-2011)

\begin{tabular}{|c|c|c|}
\hline Año & Ocupación por plazas & Ocupación en fin de semana \\
\hline 2001 & 23,08 & sin datos \\
\hline 2002 & 21,75 & sin datos \\
\hline 2003 & 20,23 & 32,17 \\
\hline 2004 & 20,75 & 33,01 \\
\hline 2005 & 20,28 & 31,71 \\
\hline 2006 & 20,94 & 33,52 \\
\hline 2007 & 20,76 & 33,63 \\
\hline 2008 & 18,42 & 30,50 \\
\hline 2009 & 16,96 & 28,52 \\
\hline 2010 & 15,72 & 26,78 \\
\hline 2011 & 15,09 & 25,17 \\
\hline
\end{tabular}

Fuente: Elaboración propia a partir de datos de la Encuesta de Alojamientos Rurales, Instituto Nacional de Estadística.

Pero al margen de ejemplos como los señalados, el desarrollo del turismo rural en España ha sido, en la mayoría de los casos, un proceso espontáneo, no planificado desde estrategias

4 Merece la pena destacar, entre todos ellos, el Maestrazgo. En el desarrollo turístico del Maestrazgo ocupa un lugar protagonista la Asociación para el Desarrollo del Maestrazgo. En la institución participa de forma activa la Asociación Comarcal de Empresarios Turísticos. Entre los múltiples proyectos que ha impulsado destacan las estrategias de desarrollo financiadas por las Iniciativas Comunitarias Leader II y Leader +, en las que el turismo ocupaba un lugar destacado, la creación del Parque Cultural del Maestrazgo, que gestiona en la actualidad y contiene uno de los seis Geoparques españoles, y la planificación y ejecución de un Plan de Dinamización Turística. Este ha propiciado la implantación del Sistema Integral de Calidad Turística Española en Destinos y la organización de una agenda cultural que incluye, entre otras ofertas, eventos musicales de diferente naturaleza. 
consensuadas y compartidas entre agentes, incentivado y fomentado por los equipos técnicos que trabajan en desarrollo rural, por las políticas públicas finalistas de subvención a la creación de oferta y por el crecimiento económico general del país. El resultado es la proliferación de experiencias con ofertas similares, con un notable déficit en productos de elevado valor añadido y que no han conseguido generar una «imagen de destino» diferenciada. Esto no ha impedido éxitos económicos que, por la falta de planificación y regulación y por crecimientos excesivos de oferta y demanda, han solido derivar en congestión, saturación y otros problemas de sostenibilidad, tal y como se ha documentado en el Parque Natural de las Sierras de Cazorla, Segura y las Villas (Araque, 2005) 5 .

Si en el mundo rural español no abundan las experiencias de desarrollos turísticos planificados, consensuados y asumidos por los agentes locales, tampoco proliferan instituciones con capacidad técnica y financiera para abordar problemas básicos para la sostenibilidad y la competitividad de los destinos como la valoración de la evolución del fenómeno, la corrección de sus impactos negativos, la evaluación de la calidad de los servicios, de la satisfacción de la experiencia turística y de la eficiencia de las inversiones en promoción o comercialización. Tal y como plantearemos a continuación esto es lo que sucede en la comarca del Nordeste Segoviano, territorio donde también se han producido avances parciales en el desarrollo turístico. Entre ellos, la recuperación, conservación y puesta en valor de parte de su patrimonio natural y cultural, si bien todavía queda un amplio camino por recorrer en este sentido. Otros son la creación de una oferta de alojamiento y restauración de calidad y de servicios especializados de turismo deportivo y gastronómico que captan un importante flujo de visitantes. Sin embargo, son múltiples las carencias que impiden calificarlo como destino turístico articulado y preparado para competir a largo plazo. No dispone de una estrategia planificada e integral de desarrollo turístico ni ha logrado consolidar una imagen de destino diferenciada. Tampoco cuenta con instituciones que velen por el buen desarrollo del turismo y apenas ha avanzado en la generación de experiencias de colaboración entre agentes. Pese a todo, sus infraestructuras de acogida siguen creciendo incluso en un período de crisis y recesión económica como 2007-2011. Este crecimiento no es sólo resultado del buen hacer de los agentes públicos y privados. Se debe, en buena medida, a las ventajas derivadas de su proximidad al gran mercado madrileño, cuestión que representa la mayor oportunidad y fortaleza territorial para el desarrollo del turismo y, a la vez, un potente factor desincentivador de la colaboración entre agentes.

\section{EL NORDESTE SEGOVIANO: ¿DESTINO TURÍSTICO O ESPACIO DONDE SE PRODUCE Y CONSUME TURISMO?}

El Nordeste Segoviano es uno más de los espacios rurales españoles cuyo futuro depende en buena medida del desarrollo turístico. Emplazado en el sector nororiental de la provincia de Segovia, sus $1.829,85 \mathrm{Km}^{2}$ se extienden por 57 municipios ${ }^{6}$ poblados por 12.000 residen-

5 Otro ejemplo puede consultarse en el trabajo de Martin. F. y Martín, I. (2006: «Problemas de sostenibilidad en destinos rurales maduros: el ejemplo de Patones», X Coloquio Geografía del Turismo, Ocio y Recreación, Asociación de Geógrafos españoles, Cuenca.

6 Alconada de Maderuelo, Aldealcorvo, Aldealengua de Santa Maria, Aldeanueva de la Serrezuela, Aldehorno, Aldeonte, Ayllón, Barbolla, Bercimuel, Bodeguillas, Campo de San Pedro, Carrascal del Rió, Casla, Castillejo de Mesleón, Castro de Fuentidueña, Castrojimeno, Castroserna de Abajo, Castroserracín, Cedillo de la Torre, 
Figura 1

LA COMARCA DEL NORDESTE SEGOVIANO

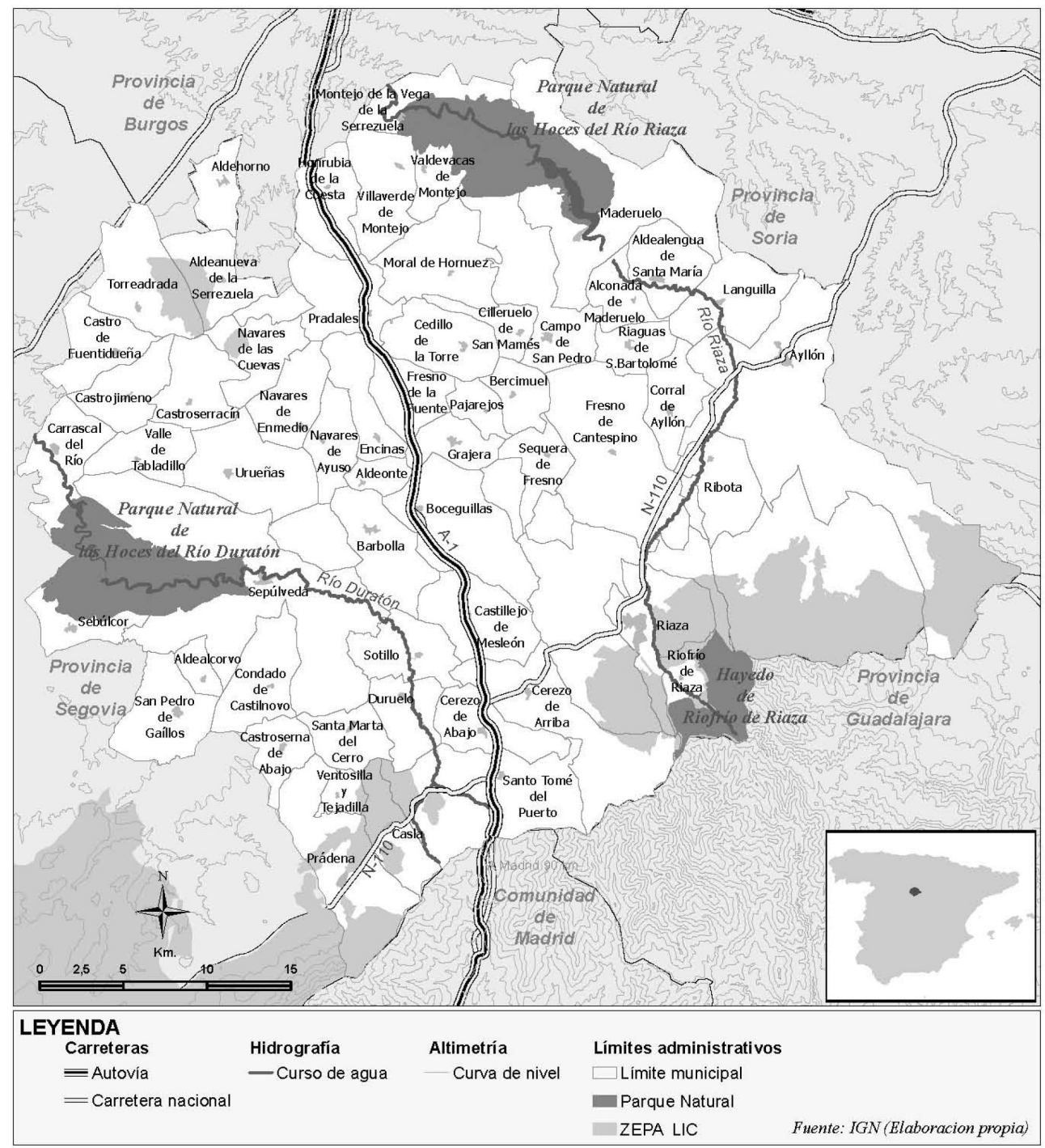

tes distribuidos en 118 asentamientos. Los límites geográficos coinciden, casi en su totalidad, con la «Comarca Agraria de Sepúlveda» delimitada en 1977 por el Ministerio de Agricultura

Cerezo de Abajo, Cerezo de Arriba, Cilleruelo de San Mames, Condado de Castilnovo, Corral de Ayllón, Duruelo, Encinas, Fresno de Cantespino, Fresno de la Fuente, Grajera, Honrubia de la Cuesta, Languilla, Maderuelo, Montejo de la Vega de la Serrezuela, Moral de Hornuez, Navares de Ayuso, Navares de Enmedio, Navares de las Cuevas, Pajarejos, Pradales, Prádena, Riaguas de San Bartolomé, Riaza, Ribota, Riofrío de Riaza, San Pedro de Gaillos, Santa Marta del Cerro, Santo Tomé del Puerto, Sebúlcor, Sepúlveda, Sequera de Fresno, Sotillo, Torreadrada, Urueñas, Valdevacas de Montejo, Valle de Tabladillo, Ventosilla y Tejadilla y Villaverde de Montejo. 
integrando parte de las históricas Comunidades de Villa y Tierra de Sepúlveda, Maderuelo, Ayllón, Fresno y Montejo. Sin embargo, su delimitación actual surge a finales del siglo XX como estrategia para captar recursos para el desarrollo rural. En concreto, en 1992 para acceder a recursos financieros de la Iniciativa Europea Leader II.

Se trata de un espacio donde abundan paisajes agrarios y naturales bien conservados, recursos hídricos y forestales y patrimonio cultural con amplias potencialidades turísticas. Por él discurre la Carretera Nacional I cuya transformación en autovía, en 1992, actuó como potente catalizador del crecimiento turístico al reducir el tiempo medio de viaje desde la conurbación madrileña de 90 a 60 minutos. Sin embargo, dos graves problemas cuestionan su supervivencia sociocultural y obstaculizan su desarrollo general y turístico: un elevado envejecimiento demográfico y un progresivo despoblamiento. La densidad demográfica (6,5 hab./Km²) le sitúan como uno de los espacios más despoblados del mundo rural español y todos los municipios mantienen escasas poblaciones, elevados grados de envejecimiento y altas tasas de dependencia.

El 29,4\% de los residentes superan los sesenta y cinco años de edad, once municipios no alcanzan los 50 habitantes, diecisiete se sitúan entre 50 y 99, dieciséis entre 100 y 199, ocho entre 200 y 399 y tan sólo cinco (Prádena, Boceguillas, Ayllón, Sepúlveda y Riaza) superan los 400. Las principales consecuencias del vacío y envejecimiento demográficos son la escasa disponibilidad de recursos humanos en edad activa, una muy reducida capacidad endógena para emprender negocios y nuevos proyectos y una carencia generalizada de fuerza de trabajo que afecta a todos los sectores de actividad, incluido el turismo. A ello se suma un claro retroceso de las actividades agropecuarias y un sector secundario raquítico formado por establecimientos agroindustriales y extractivos de muy pequeñas dimensiones y que genera escaso valor añadido. Y también aquí, tal y como sucedió en el resto de España a finales del siglo XX y primeros años del XXI, hubo un importante crecimiento de la construcción, hoy en crisis, incentivado por la demanda de segundas residencias. En paralelo, se ha registrado una fuerte expansión del turismo, actividad que hoy ocupa una posición central en el tejido productivo local y en la generación de nuevos empleos.

\section{Un potente patrimonio territorial apenas incorporado a la cadena de valor}

El modelo turístico comarcal puede definirse, en una primera aproximación, como «Turismo rural genérico». Es decir, un turismo no especializado y apenas diferenciable respecto al de otros muchos espacios rurales. La proximidad a Madrid, la singularidad y diversidad del patrimonio natural y de la arquitectura monumental y popular, la calidad ambiental y del paisaje y su gastronomía tradicional son los factores centrales sobre los que se asienta este modelo en el que predominan excursionistas de fin de semana y veraneantes en segundas residencias.

Algunos municipios como Sepúlveda y Riaza han conseguido afianzarse en el mercado como destinos gastronómicos y otros, como Carrascal del Río, Grajera y Sebúlcor, avanzan con paso firme hacia la especialización en turismo deportivo. En los últimos años ha crecido tímidamente el turismo cultural, en las cabeceras comarcales históricas, y el turismo de naturaleza ha aumentado de manera considerable en torno a los espacios naturales protegidos. Sin embargo, estos espacios muestran importantes carencias en servicios, equipamientos e 
infraestructuras de uso público para la práctica de un turismo especializado. Un problema que afecta al resto del patrimonio territorial y que evidencia el largo camino que queda por recorrer para que el Nordeste Segoviano se consolide como destino competitivo y sostenible.

El despoblamiento y el envejecimiento demográficos no sólo tienen repercusiones negativas. También generan impactos positivos para el desarrollo turístico. La baja densidad de ocupación garantiza la ausencia de estrés acústico, contaminación y congestión, recursos muy apreciados por el turista urbano post-industrial. Además, ha resguardado al territorio de dinámicas económicas que en otras zonas rurales han deteriorado el patrimonio natural y arquitectónico: aunque en los últimos años se han producido crecimientos urbanísticos, estos han sido relativamente reducidos de modo que se han preservando paisajes agrarios, ecosistemas, especies silvestres, asentamientos tradicionales de población y arquitectura vernácula. En todo ello ha tenido un papel fundamental la protección derivada de la declaración de cuatro Conjuntos Monumentales (Sepúlveda, Riaza, Ayllón y Maderuelo), de la legislación forestal y de los espacios naturales protegidos. Además, el abandono de tierras agrícolas marginales, su colonización por el monte y las repoblaciones forestales han consolidado paisajes con altos valores estéticos y recreativos.

La calidad ambiental y la presencia de abundante patrimonio territorial son factores muy valiosos para el desarrollo, afirmación especialmente pertinente en turismo rural. Ahora bien, la existencia de patrimonio no es condición suficiente para generar desarrollos turísticos. Su transformación en recurso, paso previo para la creación de productos comercializables, requiere, tal y como señala Ortega (1998), un complejo proceso de cambio de valores culturales en la sociedad y una serie de actuaciones orientadas a conservarlo, transformarlo y dotarlo de valor económico. Esto no siempre ha ocurrido en el Nordeste Segoviano porque salvo excepciones y pese a que el turismo ha adquirido en los últimos años mayor protagonismo, buena parte de su patrimonio apenas ha sido incorporado a la cadena de valor o se encuentra infrautilizado.

El crecimiento turístico de los últimos años ha sido posible gracias al efecto demostración de un puñado de emprendedores pioneros, al apoyo financiero de las políticas públicas de desarrollo rural (Martin, 1995), al marco de mercado favorable generado por el crecimiento económico español entre 1995 y 2007 y, sobre todo, a un factor geográfico-locacional, la proximidad a la conurbación madrileña. El Nordeste Segoviano tiene en la cercanía al gran mercado madrileño su principal recurso turístico. Madrid genera potentes «inercias» que garantizan un flujo permanente de visitantes, independientemente de la calidad, diversidad, singularidad y grado de articulación de los servicios turísticos. Esta renta de proximidad ${ }^{7}$ genera ventajas comparativas respecto a otros territorios que compiten en el mismo mercado, si bien buena parte de su potencial se desaprovecha. Como señala Becattini (1974) la proximidad al gran mercado, un factor externo a empresas e instituciones locales, podría potenciar en el Nordeste Segoviano procesos organizativos favorables para su articulación como destino turístico. Los estímulos del mercado madrileño podrían favorecer reacciones individuales de empresas y de conjunto que evolucionasen hacia la creación de instituciones centradas

7 El concepto hace referencia a los beneficios derivados de la cercanía a un territorio con elevado nivel de renta y población como Madrid. Deriva de los planteamientos ricardianos de renta de situación aplicados al suelo agrícola. 
en la gestión de problemas que afectan a la globalidad de los agentes y del destino turístico (Aurioles et al., 2008). También podrían propiciar la acumulación de capital social fomentando una mayor cooperación entre agentes públicos y privados en proyectos orientados a alcanzar beneficios comunes e individuales. O generar sinergias que mejoraran la eficiencia de las políticas públicas, la calidad y la competitividad global del destino. Sin embargo, esto apenas sucede porque buena parte de los agentes perciben que, sea cual fuere la articulación de la comarca como destino, sea cual sea la singularidad y la calidad de su oferta e independientemente del grado de satisfacción de los turistas con los servicios consumidos ${ }^{8}$, Madrid garantiza una afluencia elevada de visitantes. En consecuencia, su proximidad es vivida como un seguro económico que acaba por desincentivar el interés por el trabajo en común diluyendo parte de las ventajas comparativas asociadas a la renta de situación.

\subsection{Un patrimonio natural con capacidad de atracción e infrautilizado}

La comarca dispone de un patrimonio geológico de gran potencial turístico por sus valores estéticos, monumentales y educativos, además de una amplia diversidad de paisajes, un medio ambiente de calidad y una red hídrica con capacidad para sustentar diferentes actividades deportivas. El valor científico, estético y pedagógico del patrimonio geológico ha sido reconocido en trabajos especializados (Meléndez y Fúster, 2000: 420, Macpherson, 1901:105) destacando geohitos como los cañones de los ríos Duratón y Riaza y el pliegue en rodilla de Sepúlveda, además de ejemplos de meandros abandonados, paleovalles, parameras y lastras con formaciones kársticas, yacimientos de fósiles y huellas de antiguos procesos geomorfológicos como la captura fluvial del arroyo Valdepuerco por el río Duratón (Tanarro y Muñoz, 2010). Todo ello tiene su traducción en los catorce Puntos de Interés Geológicos (PIGs) catalogados en el Inventario del Instituto Geológico y Minero Español, la mitad de los existentes en la provincia 9 . Pese a ello y a que este patrimonio genera cada año un importante trasiego de público que llega para conocerlo y disfrutarlo (Sanz, 2006), en su mayor parte no ha sido incorporado a la cadena de valor turística o bien su puesta en valor ha sido incompleta, no existiendo una sola ruta temática sobre geología o geomorfología, ni infraestructuras, equipamientos o servicios específicos de interpretación de este patrimonio ${ }^{10}$.

Las cuarenta mil hectáreas forestales y la redes hidrográficas de los ríos Duratón y Riaza completan un patrimonio natural con elevado potencial recreativo que aporta a la Red Natura 2000 un total de 40.212 hectáreas distribuidas en seis Lugares de Interés Comunitario y

8 La baja relación calidad-precio en alojamientos y restaurantes es el principal problema del Nordeste Segoviano para los visitantes encuestados. Este no es un problema específico de los destinos rurales. También ha sido documentados en otros destinos como las ciudades con patrimonio próximas a Madrid. Véase el respecto el trabajo «Turismo y economía en ciudades históricas españolas», publicado por Martín, F. en 1998 en el no 47 de la revista ERIA.

9 Ermita de San Frutos, Hoces del Río Duratón, Cañón del Valle de Tabladillo, Presa de Burgomillodo, Pliegue en rodilla, Valle del río San Juan, Tonalitas (Tejadilla), Sección del cretácico superior-terciario (Sigüero), Piedemonte y Rañas de Somosierra, Hoces del Río Riaza, Falla de la ermita de Nuestra Señora de Hornuez, Sinclinal colgado de Navares de las Cuevas y Fondos de valle de la red fluvial intramiocena de Pradales y Encina).

10 Se han elaborado propuestas, como el proyecto de «Parque Geológico y Minero» promovido por Díez Herrero para la creación de un Geoparque en Valle de Tabladillo de acuerdo con los planteamiento de UNESCO (1999), que no ha avanzado de la fase de preproyecto. 
Zonas Especiales de Protección de Aves: la Sierra de Pradales, las Sierras de Ayllón y Guadarrama, las Hoces del río Duratón, las Hoces del río Riaza, los Sabinares de Somosierra y las Riberas del Río Duratón. El buen estado de conservación de los ecosistemas y la presencia de especies y hábitats de especial interés han favorecido la declaración de tres espacios naturales protegidos: el Parque Natural del Río Riaza (6.470 has.), el Parque Natural de las Hoces de Duratón (5.037 has.) y el Espacio Natural Hayedo de Riofrío de Riaza (1.930 has.). De ellos, los Parques Naturales son importantes reclamos y potentes impulsores del desarrollo turístico confirmando, en este sentido, tendencias apuntadas por Lozano, González y Martín. (2003: 187 y 188) para el conjunto de Castilla y León: en sus proximidades se concentra buena parte de los alojamientos rurales, restaurantes y empresas de turismo activo de la comarca.

El patrimonio natural ha sido utilizado tradicionalmente por los residentes para actividades de ocio y recreación como caza, recogida de setas, comidas campestres y celebración de eventos festivos. A las anteriores se suman otras de carácter ambiental y deportivo practicadas por visitantes como senderismo, cicloturismo y piragüismo realizadas en zonas puntuales del Parque del Duratón y, en menor medida, del Parque del río Riaza. También presentan claras potencialidades para actividades cinegéticas sus 115 cotos dotados con 165.666 has. ${ }^{11}$ pero, aunque todos los municipios disponen de al menos uno, pese a que la caza es una actividad muy extendida y practicada por la población local y a que todos los años llegan partidas de cazadores de otras provincias españolas, el Nordeste Segoviano no ha logrado desarrollar un segmento especializado de turismo cinegético. Junto al piragüismo, otra de las actividades recreativas que más han crecido en los últimos años es la recogida de setas en Montes de Utilidad Pública, prados, pastizales y campos de labor donde abundan especies como Lactarius deliciosus, Pleurotus eringi, Marasmius oreades y Boletus edulis. Sobre este recurso se desarrollan aprovechamientos comerciales sumergidos y actividades recreativas que ejercen una presión creciente sobre especies y hábitats cuestionando su conservación a largo plazo. En torno a las setas también se desarrolla un incipiente turismo micológico en alojamientos rurales, empresas de turismo activo y restaurantes, pero aunque para potenciar este segmento del mercado se han realizado esfuerzos en formación de recursos humanos, organización de eventos promocionales e introducción de las setas en la oferta gastronómica de los restaurantes ${ }^{12}$, no deja de ser una actividad emergente sobre la que, al igual que sucede con la caza, todavía no se ha logrado articular una oferta sólida y especializada.

\subsection{Los espacios protegidos: potentes atractivos insuficientemente imbricados en el desarro- llo turístico}

Pese a que una parte importante de los servicios turísticos se localizan en torno a los Parques Naturales del Duratón y del Riaza y aunque ha crecido el número de empresas de servicios deportivos, el aprovechamiento turístico actual de estos espacios puede calificarse, considerando las potencialidades, escaso. Antes de su declaración ambos atraían un

11 Los cotos representan el 25\% del total provincial según el Registro de Cotos de Caza de la Junta de Castilla y León.

12 El grupo de Acción Local CODINSE participó en el proyecto de cooperación interterritorial «Micología y Calidad». Organizado por quince territorios Leader+ y PRODER II con el objetivo de poner en marcha modelos de aprovechamiento sostenible de los recursos micológicos, el turismo ocupó un papel central en el proyecto. 
tímido turismo de naturaleza y soportaban múltiples actividades de ocio local. Ahora bien, fue a partir de la declaración y coincidiendo con el incremento de la demanda turística de la población española en este tipo de espacios (Plaza y Hortelano, 2005; Pulido, 2007), con la aparición de una nueva demanda de turismo rural (Martín, 1995; Cánnoves, et al., 2005), con la puesta en marcha de la primera estrategia comarcal de desarrollo rural y con el inicio de la construcción de infraestructuras de uso público cuando la actividad comienza a tener un creciente protagonismo. A partir de entonces ambos espacios pasan a convertirse, junto con la gastronomía y el patrimonio arquitectónico monumental, en los principales factores de atracción turística del territorio.

Los dos parques contienen paisajes naturales y construidos de gran poder evocador y estético $^{13}$, ríos de aguas tranquilas aptos para actividades náuticas, hábitats bien conservados y especies endémicas con capacidad de atracción como el buitre leonado, el alimoche o el búho real. Es decir, un patrimonio diverso con potencialidades para el desarrollo de múltiples actividades especializadas de turismo de naturaleza, turismo deportivo e interpretación ambiental, pero tan sólo aprovechado de manera parcial. Uno de los principales problemas en este sentido es que ambos disponen de escasas infraestructuras de uso público, sobre todo el Parque del Duratón considerando los más de veinte años transcurridos desde su declaración y la importante afluencia de público. A la insuficiente dotación de infraestructuras se une el estado de abandono de alguna de aquellas, problemas de mantenimiento y conservación de lugares puntuales, como el área recreativa del «Puente de Villaseca» (Parque del Duratón), y una muy escasa oferta de servicios especializados de interpretación ambiental y turismo educativo $^{14}$. Todo ello tiene claras incidencias en el desarrollo global del territorio y en su desarrollo turístico, situación por otro lado relativamente frecuente en los espacios rurales españoles donde es frecuente encontrar espacios naturales protegidos gestionados por técnicos poco implicados en el desarrollo local (Troitiño et al. 2005).

\subsection{Un patrimonio construido parcialmente incorporado a la cadena de valor}

Si la calidad ambiental y el patrimonio natural son dos de los principales argumentos turísticos del Nordeste Segoviano, otro tanto sucede con el patrimonio construido. Sin embargo, en la gran mayoría de los casos este patrimonio no ha sido habilitado para su uso turístico más allá de la promoción en folletos, guías o páginas web. En otros, su aprovechamiento tan sólo es parcial, incompleto o muestra múltiples carencias.

En el cañón de Duratón se localiza una de las mayores concentraciones de arte rupestre del interior peninsular (31 frisos con pinturas neolíticas) ${ }^{15}$. En el resto del territorio abundan yacimientos prerromanos, romanos y visigodos junto a un rico patrimonio monumental

13 Entre ellos destacan la Ermita de San Frutos, el Convento de la Hoz, la Ermita del Casuar y los Conjuntos Monumentales de Maderuelo y Sepúlveda.

14 El Parque del Duratón está dotado con un Centro de Interpretación, 3 áreas recreativas, 4 miradores y 5 sendas apenas equipadas. El de Riaza cuenta con un pequeño centro de interpretación, 6 sendas sin apenas infraestructuras, 3 miradores y 3 áreas recreativas. Ninguno dispone de servicio de guías culturales, ni de rutas temáticas sobre geología o patrimonio construido u otros elementos patrimoniales como pinturas rupestres. .

15 Catálogo de Bienes Culturales de la Junta de Castilla y León, http://servicios.jcyl.es/pweb/downloadDocumento.do?numbien $=10704 \&$ numdoc $=68988$ 
medieval ${ }^{16}$. El número de elementos patrimoniales declarados Bienes de Interés Cultural asciende a veintisiete (tabla 4). Cuatro son Conjuntos Histórico-Monumentales (la mitad de los existentes en la provincia), veintidós monumentos civiles y religiosos (14,6\% del total provincial) y aquí se localiza la única Zona Arqueológica catalogada de Segovia. Por sus emplazamientos en lugares estratégicos amurallados, conservación, valores estéticos, históricos e identitarios destacan los núcleos de Ayllón, Maderuelo y Sepúlveda. Por sus valores histórico-artísticos, palacios y castillos como La Casa-Palacio de Contreras y el Palacio de Vellosillo (Ayllón) y el Castillo de Castilnovo e iglesias y ermitas que representan ejemplos magníficos del románico segoviano (El Salvador y La Virgen de La Peña en Sepúlveda, San Pedro en Grado del Pico, Santa María en Riaza, San Miguel en Ayllón y La Virgen del Barrio en Navares de las Cuevas).

Tabla 4

BIENES DE INTERÉS CULTURAL EN EL NORDESTE SEGOVIANO EN 2010

\begin{tabular}{|c|c|c|c|c|c|}
\hline & \multirow[b]{2}{*}{$\begin{array}{l}\text { Conjunto } \\
\text { Histórico }\end{array}$} & \multicolumn{2}{|c|}{ Monumento } & \multirow[b]{2}{*}{$\begin{array}{c}\text { Zona } \\
\text { Arqueológica } \\
\end{array}$} & \multirow[b]{2}{*}{ Total } \\
\hline & & Religioso & Civil & & \\
\hline Ayllón & 1 & & 2 & & 3 \\
\hline Carrascal del Río & & 1 & & & 1 \\
\hline Castillejo de Mesleón & & 1 & & & 1 \\
\hline Cedillo de la Torre & & 1 & & & 1 \\
\hline Cilleruelo de San Mames & & 1 & & & 1 \\
\hline Condado de Castilnovo & & & 1 & & 1 \\
\hline Duruelo & & 1 & & & 1 \\
\hline Grajera & & 1 & & & 1 \\
\hline Maderuelo & 1 & 1 & & & 2 \\
\hline Montejo de la Vega de la Serrezuela & & 2 & & & 2 \\
\hline Moral de Hornuez & & 1 & & & 1 \\
\hline Navares de las Cuevas & & 1 & 1 & & 2 \\
\hline Prádena & & & 1 & & 1 \\
\hline Riaza & 1 & & & & 1 \\
\hline Sebúlcor & & & 1 & & 1 \\
\hline Sepúlveda & 1 & 4 & & 1 & 6 \\
\hline Valdevacas de Montejo & & 1 & & & 1 \\
\hline Total & 4 & 16 & 6 & 1 & 27 \\
\hline
\end{tabular}

Fuente: Elaboración propia a partir de información del Registro de Bienes de Interés Cultural, Ministerio de Cultura.

16 Aunque en algunos casos se utilizan en las herramientas de promoción turística, en la actualidad no existe un solo yacimiento arqueológico visitable. Tampoco se han puesto en valor las pinturas rupestres y son escasas las iglesias románicas con horarios de visita adaptados a las necesidades del turista. 
La comarca de Nordeste Segoviano también cuenta con un patrimonio arquitectónico popular relevante. El sector meridional destaca por la homogeneidad de los modelos de asentamiento, el central por tratarse de un espacio de transición y en conjunto incluyen ejemplos de cuatro de los trece modelos de asentamientos tradicionales de Castilla y León (Benito, 1998):

- el modelo de «Núcleos de agrupaciones de edificación compacta» (Valle de Tabladillo y Estebanvela),

- el de «Núcleos de baja densidad y edificación con corral delantero» (Tejadilla, Martín Muñoz de Ayllón, Madriguera, Alquite, Becerril, Serracín, El Muyo, El Negredo y Villacorta, Valvieja, Prádena, El Olmillo y Tanarro),

- el definido como «Núcleos de disposición continua, alta densidad y edificación con corral posterior» (Fresno de Cantespino, Becimuel, Grajera, Fresno de la Fuente, Perorrubio y Vellosillo).

- El denominado «Núcleos cercados y de carácter urbano» con los ejemplos sobresalientes de Sepúlveda, Ayllón y Maderuelo.

Los núcleos de población, la arquitectura monumental y la popular aportan múltiples potencialidades turísticas por sus valores estéticos y culturales. Generan valor añadido a empresas e instituciones culturales, de restauración o alojamiento emplazadas en antiguos edificios rehabilitados y contienen valores pedagógicos por ser el resultado de prácticas constructivas adaptadas a la topografía y a la diversidad litológica. Sin embargo, uno de los déficits turísticos comarcales es el escaso o inadecuado aprovechamiento turístico de esta riqueza. A las dificultades para visitar monumentos y edificaciones porque no han sido habilitados para desempeñar esta función o porque los horarios son muy restringidos ${ }^{17}$, se suman la inexistencia de productos específicos, como rutas temáticas, y de señales orientativas y paneles informativos en los edificios populares más representativos, al contrario de lo que ocurre con los monumentales. A todo ello hay que unir su deterioro y en múltiples casos desaparición por colapso o expolio ${ }^{18}$. El desinterés y la incapacidad económica de los propietarios para financiar la habilitación para las visitas, mantener sistemas de vigilancia y guías físicos que las posibiliten explican en parte estos problemas. Cuestiones que tampoco ayudan a resolver las políticas públicas finalistas de desarrollo rural y turístico porque no consideran subvencionables la prestación de servicios, es decir, la contratación de personal para mantenimiento, control y acompañamiento de las visitas.

Este territorio de vocación histórica ganadera todavía mantiene buen número de edificaciones e infraestructuras agropecuarias destinadas a labores agrícolas, cerramiento de ganado y trabajos relacionados con su explotación. Sin embargo fraguas, fuentes, lavaderos, cercas de piedra, molinos, cuadras, tenadas, apriscos, esquileos, palomares y bodegas no han generado un solo producto turístico, a excepción de la fragua de Castillejo de Mesleón, reconvertida en pequeño museo. Buena parte de él, incluidos ejemplos emplazados en el Parque Natural de las Hoces del Duratón, se encuentra en grave proceso de desaparición por

17 Aunque este es un problema generalizado existen excepciones en Sepúlveda, Ayllón Riaza.

18 La desaparición, por demolición y/o sustitución, de viviendas tradicionales del Valle de Tabladillo es un claro ejemplo de este tipo de problemas. 
Tabla 5

TRATAMIENTO DEL PATRIMONIO ARQUITECTÓNICO POPULAR EN EL PLANEAMIENTO URBANO

\begin{tabular}{|c|c|c|}
\hline $\begin{array}{l}\text { Municipios según tipo de } \\
\text { Planeamiento }\end{array}$ & $\begin{array}{c}\mathrm{N}^{0} \text { de } \\
\text { municipios }\end{array}$ & Tratamiento \\
\hline $\begin{array}{l}\text { Municipios sin Planeamiento espe- } \\
\text { cífico regulados por las Normas } \\
\text { Subsidiarias Provinciales de } 1996\end{array}$ & 31 & No se aborda \\
\hline \multirow[b]{3}{*}{ Con Delimitación de Suelo Urbano } & 3 & No se aborda \\
\hline & 2 & $\begin{array}{l}\text { En ambos se plantea la cuestión pero } \\
\text { sólo en uno se ha elaborado un Catá- } \\
\text { logo de Bienes Protegidos }\end{array}$ \\
\hline & 1 & $\begin{array}{l}\text { Tratamiento pormenorizado que con- } \\
\text { templa la conservación de la morfo- } \\
\text { logía urbana y edificatoria incluyendo } \\
\text { bodegas y otro patrimonio }\end{array}$ \\
\hline \multirow{3}{*}{ Normas Urbanísticas Municipales } & 2 & No abordan la cuestión \\
\hline & 1 & $\begin{array}{l}\text { Reconoce el interés de este patrimonio } \\
\text { pero tan solo plantean un tratamiento } \\
\text { genérico de protección ambiental }\end{array}$ \\
\hline & 3 & $\begin{array}{l}\text { Disponen de catálogos de elementos } \\
\text { patrimoniales a proteger }\end{array}$ \\
\hline \multirow[b]{2}{*}{ Normas Subsidiarias } & 2 & No se aborda la cuestión \\
\hline & 11 & $\begin{array}{l}\text { Contienen propuestas e instrumentos } \\
\text { de conservación aunque con desigual } \\
\text { tratamiento }\end{array}$ \\
\hline
\end{tabular}

Fuente: Elaboración propia a partir del análisis del planeamiento municipal.

derrumbamiento o expolio. Otra ha sufrido desafortunadas trasformaciones o se encuentra en un avanzado estado de degradación que puede desembocar en pérdida irreversible (Martín, 1998). El impacto de los procesos de renovación del parque de viviendas y la escasa sensibilidad al respecto de propietarios y administraciones locales explican, en buena medida, esta situación. También un tratamiento inadecuado en los instrumentos de planeamiento municipal (tabla 5):

- en los 31 municipios sin planeamiento específico y cuyo desarrollo urbanos es regulado por las Normas Subsidiarias Provinciales, estas no abordan el problema a escala local,

- de los 6 que disponen de Delimitaciones de Suelo Urbano, tres se encuentran en idéntica situación, dos reconocen los problemas aunque sólo uno ha elaborado un Catálogo de Bienes Protegidos, y tan sólo en el restante se contempla la conservación de la morfología urbana y edificatoria, 
- de los 6 municipios con Normas Urbanísticas Municipales dos tampoco abordan el problema, en uno, pese a reconocer el notable interés de este patrimonio, apenas plantean un tratamiento genérico de protección ambiental y sólo tres cuentan con catálogos de elementos patrimoniales a proteger,

- por último, de los 13 casos con Normas Subsidiarias en dos tampoco se aborda la cuestión y sólo en los once que restan, entre los que se encuentran los cuatro Conjuntos Monumentales, se plantean propuestas e instrumentos de conservación aunque con desigual tratamiento.

Todo ello lleva a concluir, como señala Mata (2008), en la necesidad de integrar la conservación de la arquitectura popular en el planeamiento urbano más allá de los núcleos declarados conjuntos monumentales ${ }^{19}$. Una cuestión directamente relacionada con otro problema tratado más adelante: la ausencia de una estrategia común de desarrollo turístico planificada, consensuada y asumida por los agente locales que propicie, desde intereses compartidos, este nuevo tratamiento en el planeamiento.

\section{Las infraestructuras básicas de acogida: crecimiento y difusión territorial}

Hasta finales de la década de los ochenta del siglo pasado el turismo en el Nordeste Segoviano era una actividad de carácter tradicional, practicada por antiguos pobladores emigrados a la ciudad y basada en el veraneo de emigrantes y la segunda residencia ${ }^{20}$. A partir de entonces una serie de factores favorecieron el desarrollo de un nuevo modelo de turismo comercial sustentado en el aprovechamiento de recursos locales, gestionado a escala artesanal, difuso en su distribución territorial y similar al que por las mismas fechas surgió en el resto del mundo rural español. El efecto demostración de otras experiencias españolas, las oportunidades generadas por la proximidad del gran mercado madrileño, la llegada de fondos europeos para el desarrollo rural, la declaración del Parque Natural de las Hoces del Duratón y las iniciativas de un primer puñado de emprendedores fueron los detonantes del proceso (Martín, 1995).

Los noventa fueron años de creación de infraestructuras básicas hasta entonces inexistentes salvo en cabeceras comarcales (Riaza, Sepúlveda y Ayllón) y núcleos emplazados en torno a la carretera Nacional I (Boceguillas, Cerezo de Abajo, Santo Tomé del Puerto y Carabias). También en aquellos años surgieron las primeras empresas de turismo activo en Sebúlcor y Grajera. En todo ello tuvo una incidencia central la labor del Grupo de Acción Local

19 Una de las escasas iniciativas orientadas a proteger el patrimonio construido es un «Plan Especial de Protección de la Arquitectura Popular» a aplicar en las zonas de los pueblos negros y rojos de la Sierra de Ayllón. El proyecto, impulsado por CODINSE, se enmarca en el Plan PAHIS 2004-2012 del Patrimonio Histórico de Castilla y León.

20 Los primeros antecedentes documentados de turismo comercial se dan en Sepúlveda, donde ya en la década de los años cincuenta del siglo XX llegaban excursionistas desde Madrid para consumir el tradicional asado de cordero. En Riaza, los primeros antecedentes de turismo de montaña yII residencia surgen vinculados a la presencia de la estación del ferrocarril Madrid-Aranda de Duero. A partir de los años setenta del siglo XX también surge un turismo de nieve tras la construcción de la estación de esquí de La Pinilla, hecho que potencia la creación de segundas residencias. 
«CODINSE», con la ejecución de la primera estrategia de desarrollo comarcal cofinanciada por la Iniciativa Comunitaria Leader II.

Tabla 6

EVOLUCIÓN DE LA INFRAESTRUCTURA TURÍSTICA (2000-2010)

\begin{tabular}{|c|c|c|c|c|c|c|}
\hline & \multicolumn{3}{|c|}{$\mathbf{N}^{\mathbf{0}}$ de establecimientos } & \multicolumn{3}{c|}{$\mathbf{N}^{\mathbf{0}}$ de plazas } \\
\hline & $\mathbf{2 0 0 0}$ & $\mathbf{2 0 0 7}$ & $\mathbf{2 0 1 0}$ & $\mathbf{2 0 0 0}$ & $\mathbf{2 0 0 7}$ & $\mathbf{2 0 1 0}$ \\
\hline Alojamiento & 46 & 105 & 141 & 976 & 2498 & 2844 \\
\hline Restauración & 64 & 99 & 106 & 4.852 & 7.556 & 7.767 \\
\hline
\end{tabular}

Fuente: Elaboración propia a partir de información del Instituto de Estadística de la Junta de Castilla y León y del Instituto Nacional de Estadística.

En 2000 funcionaban 46 alojamientos con 976 plazas, dieciocho municipios contaban con oferta, seis (Ayllón, Carrascal del Río, Boceguillas, Riaza, Santo Tomé del Puerto y Sepúlveda) concentraban el 59\% del total y había un claro equilibrio entre alojamientos convencionales y establecimientos rurales. En los siete años siguientes la actividad creció de forma intensa, se diversificó y extendió por el territorio. En 2007 había 105 establecimientos (128\% de incremento), 2.498 plazas $(155,9 \%)$ y 31 municipios con oferta. Entre 2007 y 2010, en un período de recesión económica, las tendencias se mantuvieron aunque ralentizadas: aumentó el 8,5\% el número de establecimientos, el 13,85\% el de plazas y eran 32 los municipios con oferta. Procesos similares afectaron a la restauración, la actividad turística con más larga trayectoria, la que cuenta con mayor número de establecimientos y la más difundida en la comarca. También aquí se produjo un fuerte crecimiento y expansión territorial. En 2000 había 64 restaurantes, con 4.852 plazas, distribuidos en 24 municipios. Siete años después las cifras habían aumentado a 99 (54,7\% de incremento), a $7.556(58,8 \%)$ y a 25 respectivamente. Entre 2007 y 2010 los incrementos fueron del 7,07 \%, del 2,8\% y eran 27 los municipios que contaban con estos servicios. Junto a su amplia distribución espacial, la restauración muestra una fuerte concentración en municipios localizados en torno a la Carretera Nacional I y, sobre todo, en Sepúlveda y Riaza. Ambos forman parte de los principales destinos gastronómicos de fin de semana de los madrileños, tienen una dilatada trayectoria gastronómica y concentran en torno al $41 \%$ de establecimientos y el $43 \%$ de las plazas de la comarca.

Uno de los factores que explican la amplia presencia territorial de la restauración y su intenso crecimiento es su papel como actividad refugio dentro del sector, siendo frecuentes casos de empresarios que inician proyectos de alojamiento o servicios complementarios y con el tiempo amplían sus negocios con restaurantes ${ }^{21}$. El aumento significativo del número de Centros de Turismo Rural, posadas rurales y hoteles, categorías de alojamiento que por normativa precisan ofrecer este tipo de servicios, también explica su amplia implantación. Sin embargo, el más importante es la capacidad de atracción de una tradición documentada al menos desde mediados del siglo XIX, el asado de cordero, basada en la calidad de la materia

21 Las encuestas realizadas muestran que, con el paso del tiempo, la tendencia general entre los empresarios de turismo deportivo es complementar su oferta con servicios de restauración. 
prima de esta tierra ganadera y en un valioso patrimonio cultural inmaterial: el saber hacer de sus asadores. Ambas cuestiones han impulsado la creación de un sector dinámico, con fuerte poder de atracción y capacidad para generar una imagen de destino gastronómico que beneficia al conjunto de la comarca.

En otro de los pilares del turismo, el conjunto de servicios aglutinados bajo la denominación genérica de «complementarios», el Nordeste Segoviano muestra un muy escaso desarrollo en servicios de naturaleza y culturales y una elevada especialización, aunque sólo en un número reducido de municipios, en actividades deportivas. En 2008 operaban en la provincia catorce de las cuarenta y dos empresas de turismo activo incluidas en el registro oficial de la Junta de Castilla y León (33,3\% del total en una de las regiones de mayores dimensiones de Europa). Diez de ellas en el Nordeste Segoviano ${ }^{22}$, situación que no había variado sustancialmente en 2010. Las actividades se desarrollan en tres municipios afectados por el Parque Natural del Duratón (Sebúlcor, Carrascal del Río y Sepúlveda) y dos situados al este (Grajera y Fuente del Fresno), a escasa distancia de los anteriores. El grueso de la demanda proviene de Madrid y los servicios son proporcionados por pequeñas empresas, inicialmente especializadas en una sola actividad (piragüismo, paseos a caballo o cars) que, con el tiempo, generan otros servicios deportivos, de restauración o de alojamiento como estrategia de adaptación a los cambios de la demanda y de captación de nuevos mercados.

Frente al importante desarrollo del turismo deportivo y pese a existir una elevada demanda potencial de actividades culturales como exposiciones, conciertos de música o representaciones escenográficas, el Nordeste Segoviano no dispone de una oferta mínima ni permanente de servicios turístico-culturales, ni de empresas especializadas en el sector 23. Tampoco ha desarrollado una oferta de servicios de turismo de naturaleza, más allá de los escasos proporcionados por los Centros de Interpretación de los Parques Naturales y por algunas empresas de turismo deportivo que los incluyen de forma secundaria en sus propuestas. Todo ello refleja un claro déficit de la oferta turística comarcal y una debilidad significativa en el proceso de consolidación del territorio como destino turístico competitivo y sostenible a largo plazo.

\section{Multiplicidad de agentes sin proyecto compartido}

En la comarca actúan diferentes instituciones públicas con competencias en turismo y varios denominadores comunes: disponen de escasos medios financieros y humanos, apenas tienen capacidad de intervención y actúan de manera independiente y descoordinada. Junto a la Administración General del Estado, La Junta de Castilla y León y la Diputación Provincial $^{24}$ operan, impulsando medidas de fomento del turismo, seis mancomunidades ${ }^{25}$, tres

22 Estas cifras señalan a Segovia como la provincia castellano-leonesa con mayor especialización en este segmento del mercado y al Nordeste Segoviano como el territorio más especializado de la provincia

23 Este es uno de los principales déficits recogidos en las entrevistas y encuestas realizadas en los proyectos de investigación de TERRITUR.

24 Las tres tienen competencias en turismo y en ámbitos con gran incidencia en la actividad como medio ambiente, empleo, fomento económico, urbanismo, cultura y deportes .

25 «Hontanares», «Nordeste», «Nuestra Señora de Hornuez», «Tres Cruces», «Municipios de la Sierra»y «Municipios de La Pedriza». 
Comunidades de Villa y Tierra («Fresno de Cantespino», «Maderuelo» y «Sepúlveda»), una asociación sin ánimo de lucro CODINSE y los entes responsables de la gestión de los Parques Naturales de las «Hoces del Río Duratón» y «Hoces de Río Riaza». De ellas, al margen de la administración central, autonómica y municipales, tres tienen incidencias directas en el desarrollo turístico:

- CODINSE, grupo de acción local creado en 1992 para la gestión de proyectos de desarrollo.

- Las Juntas Rectoras de los Parques Naturales de las Hoces del Río Duratón y del Río Riaza, gestoras de las actividades de uso público de estos espacios.

- La Comunidad de Villa y Tierra de Sepúlveda que con un muy escaso presupuesto y una reducida dotación de recursos humanos ha llevado a cabo acciones de promoción, dinamización del sector restauración y dotación de infraestructuras.

Los problemas socioeconómicos de la comarca han llevado a poner en marcha diversas iniciativas para impulsar su desarrollo. Parte de ellas han sido planificadas por CODINSE, institución gestora de proyectos financiados por las Iniciativas Comunitarias Leader II, Leader + y NOW y por otras políticas nacionales, que en la actualidad gestiona la aplicación de programa de desarrollo comarcal financiado por FEADER. Entre las actividades promovidas por CODINSE el turismo ha ocupado un lugar central, sobre todo en sus primeros años de funcionamiento, durante el período de aplicación de la Iniciativa Leader II (1994-1999). En este tiempo apoyó con subvenciones a promotores de infraestructuras básicas de acogida, financió la creación de pequeños museos y la instalación de paneles en rutas. A partir de 2000, con la aplicación de las estrategias de desarrollo financiadas por Leader+ y FEADER, sus actuaciones en turismo se restringieron, centrándose en la diversificación de la oferta, la calidad e innovación en la red de alojamientos y la instalación de paneles en monumentos.

Junto a CODINSE, sin apenas coordinación, actúan ayuntamientos, Diputación Provincial, Junta de Castilla y León y Comunidad de Villa y Tierra de Sepúlveda. Esta última ha centrado su trabajo en acciones de promoción, instalación de paneles informativos en los núcleos de población, fomento de la restauración y en la elaboración de un pre proyecto, que no prosperó, para solicitar un Plan de Dinamización de Producto Turístico. A ellos hay que sumar otros actores públicos como la Delegación Territorial de Medio Ambiente de Segovia, responsable en última instancia de la gestión de los Parques Naturales del Duratón y Riaza, por su papel en la dotación de infraestructuras de uso público de estos espacios protegidos que son, en la actualidad, dos de los principales atractivos del territorio. Sin embargo, tal y como se ha señalado, en el Nordeste Segoviano se constata un problema extendido en el resto de espacios rurales españoles con espacios naturales protegidos: la escasa imbricación de estos últimos en los procesos de desarrollo general y turístico. Hasta tal punto esto es así que en las estructuras de toma de decisiones de los parques son minoría los agentes locales directamente implicados en el desarrollo ${ }^{26}$, mientras que los responsables de los espacios

26 El ejemplo del Parque de las Hoces del Río Duratón es paradigmático al respecto: de los diecisiete miembros de su Junta Rectora tan sólo siete (tres alcaldes, dos agricultores-ganaderos, un propietario de tierras y un representante de la Diputación provincial) son agentes locales. 
protegidos no se han incorporado a las estructuras de gestión de las instituciones competentes en desarrollo, siendo paradigmática su ausencia en CODINSE.

La descoordinación, la ausencia de una estrategia de actuación compartida y la yuxtaposición de actuaciones ejecutadas por diferentes agentes se traducen en la duplicación de inversiones con similares objetivos y otras ineficiencias en la aplicación de las políticas públicas. Un buen ejemplo son las señales de información turística emplazadas en las entradas de los pueblos que forman la Comunidad de Villa y Tierra de Sepúlveda. Allí, CODINSE instaló paneles informativos que incluían un mapa con los recursos turísticos más importantes y pocos años después la Comunidad de Villa y Tierra colocó, a escasos metros, otros similares que no aportan valor añadido.

Junto a la escasa coordinación entre agentes el déficit en Capital Social es otro grave obstáculo para el desarrollo general y turístico del Nordeste Segoviano. El Capital Social incluye el conjunto de valores, actitudes, normas y redes relacionales que operan en la organización social incidiendo directamente en los procesos de desarrollo facilitando o bloqueando escenarios para la adopción de acciones estratégicas que requieren coordinación, confianza y trabajo en común entre los agentes locales (Gordon 2006). Si entendemos este concepto en un sentido amplio, incluyendo los mecanismos y las relaciones personales e institucionales básicas para la integración intracomunitaria, la capacidad y autonomía de los individuos y agentes para relacionarse con otros externos a la comunidad, las sinergias entre instituciones, su eficiencia, confiabilidad y credibilidad (Moyano, 2005), la conclusión no puede ser más pesimista. En la comarca, salvo muy escasas excepciones, apenas existen relaciones de cooperación entre agentes públicos y/o privados ${ }^{27}$. Tampoco se han creado espacios para el debate y la reflexión sobre los problemas de desarrollo turístico y la desconfianza hacia «los otros» está extendida, siendo una actitud generalizada entre agentes públicos y privados, entre los agentes privados que operan en el sector y entre las instituciones públicas con competencias en la materia. Todo ello configura un cúmulo formidable de obstáculos a la hora de abordar proyectos en común, a los que se suma la ausencia de liderazgo. Este papel podría corresponder a CODINSE, pero el reconocimiento de la institución por parte de los agentes es frágil ${ }^{28}$, sobre todo a medida que nos alejamos del municipio donde tiene su sede.

En definitiva, las carencias de liderazgo y capital social ensombrecen las perspectivas del desarrollo turístico futuro y remiten a otro problema central en la creación de un destino: la ausencia de una estrategia global de desarrollo turístico. La comarca no ha sido capaz de elaborar un proyecto compartido que defina un rumbo con objetivos consensuados y asumidos por los agentes. No dispone de herramientas ni métodos de trabajo orientados a transformar un territorio donde se producen y consumen servicios turísticos en un destino articulado,

27 La Asociación «Asadores de Lechazo de Castilla y León» es la excepción más notable. De ámbito nacional y creada por empresarios locales, desarrolla una intensa actividad turística. Sus miembros locales desempeñan una importante labor en el mantenimiento de la imagen de calidad de su gastronomía que beneficia al conjunto de operadores comarcales. Conforma un grupo activo de agentes con experiencia sectorial interesados en un desarrollo turístico de calidad, es uno de los principales interlocutores del sector con las administraciones públicas y, en definitiva, una de las pocas redes de agentes comarcales organizada en torno a objetivos compartidos.

28 En el momento de elaboración de la estrategia de desarrollo a financiar por FEADER, cinco municipios (Maderuelo, Riofrío de Riaza, Sequera de Fresno, Torreadrada y V. de Tabladillo) no eran socios de la asamblea de CODINSE. En sentido inverso, también conviene señalar que el número de asociados en las mismas fechas superaba los doscientos incluyendo instituciones (públicas y privadas) y personas a título individual. 
competitivo y sostenible a medio y largo plazo. Tampoco ha avanzado en la creación de una imagen de marca territorial, de una imagen reconocida de destino turístico. Si, como señala Puche (2010:149), junto a variables personales e individuales los tres factores que en combinación generan la «imagen de marca» de un destino turístico son las experiencias secundarias (opiniones o recomendaciones de terceros), el nombre promocional y los medios de comunicación, en el caso del Nordeste Segoviano estas dos últimas apenas se han trabajado o se han abordado de manera parcial y sin continuidad en el tiempo.

\section{CONCLUSIONES}

En el Nordeste Segoviano asistimos en los últimos veinte años a procesos similares a los registrados en otras zonas rurales españolas: un notable crecimiento del turismo, la expansión de la actividad al conjunto del territorio y aumentos muy significativos del número de empresas y de su capacidad de acogida. Sin embargo, pese a que en algunos municipios existe una larga tradición turística y a otros avances registrados en la puesta en valor del patrimonio y la generación de productos y servicios, la comarca no puede ser considerada como un destino consolidado y preparado para competir a largo plazo.

En este territorio se constatan cuatro problemas generalizados en el mundo rural español. El primero, la incapacidad para articularse como destino turístico diferenciado y superar un modelo de «turismo rural genérico». Salvo casos puntuales de especialización en turismo deportivo, de naturaleza o gastronómico, no se han creado argumentos turísticos reconocibles y diferenciables respecto a otros territorios. Después de más de veinte años de desarrollo turístico buena parte del patrimonio territorial no ha sido puesto en valor, otro se encuentra infrautilizado y existen claros déficits en servicios de turismo de naturaleza y cultural. Pese a la riqueza y diversidad patrimonial no se ha conseguido elaborar productos complejos integrados por diferentes recursos, tematizados, con elevado valor añadido, que incorporen a la cadena de valor patrimonio en riesgo de degradación y dirigidos a nichos especializados de demanda. Queda, por tanto, un largo camino por recorrer en este apartado, especialmente en la puesta en valor de la arquitectura popular, el patrimonio geológico, forestal y cinegético y los espacios protegidos. El segundo, la ausencia de una estrategia de desarrollo turístico planificada que, considerando las tendencias generales y las potencialidades endógenas, plantee objetivos compartidos y asumidos por el conjunto de agentes, defina propuestas globales y coherentes de promoción y comercialización y promueva medidas para incorporar la conservación del patrimonio construido popular al planeamiento urbano. El tercero, la falta de estructuras de gestión operativas, activas y eficientes que fomenten el desarrollo turístico, identifiquen, anticipen y corrijan los problemas derivados de este desarrollo y en las que estén presentes, reflexionen y colaboren agentes públicos y privados. En este sentido destaca el papel ausente de los responsables de la gestión de los espacios naturales protegidos. El cuatro es la incapacidad para proyectar una imagen de marca territorial reconocida por el mercado. Hoy pueden gozar de cierto reconocimiento las marcas «Sepúlveda», «Riaza»o «Duratón», pero no sucede lo mismo con la marca «Nordeste Segoviano», es decir, aquella que representa al conjunto de la comarca como destino turístico. 
En definitiva, tal y como sucede en la mayoría de nuestras zonas rurales, más allá de su condición de espacio donde se produce y consume turismo el Nordeste Segoviano no puede ser considerado un destino turístico completo, cuestión que compromete la sostenibilidad económica de la actividad en un entorno de competencia en aumento y cuya resolución requiere una aproximación sistémica al problema (Vera et al. 1997; Barrado, 2004). El escenario de incremento de la competencia en el turismo rural español, de restricciones presupuestarias de las políticas nacionales y de disminución de recursos europeos obliga al Nordeste Segoviano y al resto de espacios rurales españoles a apostar en el diseño de fórmulas de trabajo innovadoras. Estas deberían incluir, partiendo de la puesta en valor de los recursos endógenos con criterios de sostenibilidad ambiental y socioeconómica, proyectos viables orientados a la especialización, la tematización y la diferenciación, la aplicación de criterios que maximicen la eficiencia de las inversiones y nuevas fórmulas de financiación que incluyan mayores cuotas de autofinanciación y compromiso activo de los actores locales. Todo ello requiere un plan de acción con estrategias de desarrollo planificadas, debatidas, compartidas y asumidas por los agentes, que definan agendas de trabajo y objetivos jerarquizados, que incluyan acciones dirigidas a generar productos con elevado valor añadido que articulen diferentes recursos locales, mecanismos y sistemas de control y seguimiento del desarrollo turístico e instrumentos para fortalecer y difundir la imagen de marca del destino. Cuestiones que, en definitiva, requieren trabajo en común, colaboración, compromiso activo, confianza entre agentes y liderazgo. Es decir, superar uno de los principales problemas para el desarrollo del turismo en los territorios rurales españoles: su profundo déficit en capital social.

\section{BIBLIOGRAFÍA}

ALMEIDA F., COLL, M., BRUNET, P. y MONTESERÍN, O. (2005): «Los planes de excelencia y dinamización turística (PEDT), un instrumento de cooperación a favor del desarrollo turístico». Boletín de la Asociación de Geógrafos Españoles, n 39, 201-226.

ARAQUE, E. (2005): «Las nuevas funciones recreativas de los montes. Reflexiones desde un escenario privilegiado: las sierras de Segura y Cazorla». Cuadernos de Turismo, $\mathrm{n}^{\circ}$ $15,7-25$.

AURIOLES, J., FERNÁNDEZ, C. Y MANZANERA, E. (2008): «El distrito turístico» en «Los Distritos Industriales». Mediterráneo Económico, n 13, Fundación Cajamar.

BARRADO, D. (2004): «El concepto de destino turístico. Una aproximación geográficoterritorial». Estudios Turísticos, nº ${ }^{\circ}$ 160, 45-68.

BECATTINI, G. (1979): «Dal «settore» industriale al «distretto» industriale. Alcune considerazioni sull'unità di indagine dell'economia industriale». Rivista di economia e politica industriale, vol. 5, $\mathrm{n}^{\circ} 1,7-21$.

BENITO, F. (1998): Arquitectura tradicional de Castilla y León. Junta Castilla y León.

BUTLER, R. (1980): «The Concept of a Tourist Area Cycle of Evolution: Implications for Management of Resources». Canadian Geographer, vol. 24, nº 1, 5-12.

BRITO, M. (2009): Las ciudades históricas como destinos patrimoniales. Potencialidades y requisitos. Una mirada comparada: España y Brasil. Sevilla, Instituto Andaluz del Patrimonio Histórico. 
CÁNOVES, G. y VILLARINO, M. (2005): «Turismo rural en España: Paisajes y usuarios, nuevos usos y nuevas visiones». Cuadernos de Turismo, $\mathrm{n}^{\circ}$ 15, 63-76.

DE LA CALLE, M. y GARCÍA, M. (2006): «Turismo en el medio rural, conformación y evolución de un sector productivo en plena transformación: el caso del Valle del Tiétar (Avila)». Cuadernos de Turismo, nº. 17, 75-102.

DONAIRE, J.A. (1998): La reconstrucción de los espacios turísticos. La geografía del turismo después del fordismo, disponible en http://www.diba.cat/documents/74353/74446/turismelocal-forum_natura-donaire2-pdf.pdf.

FORONDA, C. (2006): «Repercusiones de los programas de desarrollo rural en el campo andaluz», en Turismo y cambio territorial: ¿eclosión, aceleración, desbordamiento?, (Lacosta Aragües, J., Coord.), Universidad de Zaragoza, 119-130.

ZOIDO, F. y OJEDA, J. (2003): «Diversidad, desigualdad y cohesión territorial», en Geografía de Andalucía (López Ontiveros, A., coord.). Barcelona, Ariel, 777-812.

FUENTES, R. (1999): «Los Planes de Dinamización: estrategia de desarrollo turístico de destinos emergentes», en La actividad turística española en 1998 (Bote Gómez, V. Coord.), 551-562.

GINES, J. (2007): «Las cuevas turísticas de las islas Baleares: antecedentes y estado de la cuestión», en Cuevas turísticas: aportación al desarrollo sostenible, Instituto Geológico y Minero de España, 17-30.

GÓMEZ, J. y RICO, M. (2005): «La participación empresarial de la mujer en las iniciativas de turismo rural en Castilla y León». Estudios Turísticos, nº 166, 97-114.

GONZÁLEZ-RÍOS, M. y RAMÍREZ-TRILLO, F. (2007): «Historia de las cuevas turísticas en España», en Cuevas turísticas: aportación al desarrollo sostenible. Instituto Geológico y Minero de España, 9-15.

GORDO, P. (2011): «Las políticas territoriales de desarrollo rural de la Unión Europea: un balance de veinte años en Castilla y León». Estudios de Economía Aplicada, vol. 29, nº 1, 7-30.

GORDON, S. (2006): «Confianza, reciprocidad y asociatividad: ¿relación indispensable para el desempeño institucional?». Estudios Sociológicos, vol. 24, nº. 2, 397-421.

IOANNIDES, D. y DEBBAGE, K. (1997): «Post-Fordism and Flexibility: The travel industry polyglot». Tourism Management, v.18, $\mathrm{n}^{\circ}$ 4, 229-241.

JOLÍN, V. (2002): «La comarca como destino turístico: el turismo rural en el marco de los programas LEADER + y PRODER II». Actualidad Leader, $\mathrm{n}^{\circ}$ 18, 28-31.

JORDÁ, R., JORDÁ, L. Y SAN ROMÁN, L. (2010): Estado actual de las minas museo en España. Disponible en http://speleominas.blogspot.com.es/2011/03/minas-turisticas-deespana.html

KNAFOU, R. (2006): «El turismo, factor de cambio territorial: evolución de los lugares, actores y prácticas a lo largo del tiempo», en Turismo y cambio territorial: ¿eclosión, aceleración, desbordamiento?, (Lacosta, A., Coord.), Universitarias Zaragoza, 19-30.

LÓPEZ-GUZMÁN, T. y SÁNCHEZ, S. (2008): «La creación de productos turísticos utilizando rutas enológicas». Pasos: Revista de turismo y patrimonio cultural, v. $6, \mathrm{n}^{\circ} 2$, $159-171$.

LÓPEZ, J. (2008): «El turismo ornitológico en el marco del Postfordismo:, una aproximación teórico-conceptual». Boletín de la Asociación de Geógrafos Españoles, n 21, 85-111. 
LOZANO, Mª J., GONZÁLEZ, V. y MARTÍN, A. (2003): «Los espacios protegidos como factor de localización del turismo rural en Castilla y León». Serie Geográfica, nº 11, 177-190.

MACPHERSON, J. (1901): Geología. Barcelona, Manuales Soler.

MARTÍN, F. (1995): Mercado de Trabajo en Áreas Rurales. Un enfoque integrador. Madrid, Ministerio de Agricultura, Pesca y Alimentación, Serie Estudios nº 110.

MARTÍN, F. (1998): «Desarrollo y patrimonio arquitectónico en el Nordeste Segoviano I». El Nordeste de Segovia, $\mathrm{n}^{\circ}$ 8, Campo de San Pedro, CODINSE.

MATA, R. (2008): «El paisaje, patrimonio y recurso para el desarrollo territorial sostenible. Conocimiento y acción pública». Arbor, nº 729, 155-172.

MELÉNDEZ B. y FÚSTER, J.M. (2000): Geología. Madrid, Paraninfo.

MONSERIN, O. (2008): «La interpretación y puesta en valor del territorio: los Planes de Dinamización Turística», en Destinos Turísticos: viejos problemas, ¿nuevas soluciones?. (Troitiño, M.A. et. al., Coord.), Asociación de Geógrafos Españoles, 269-280.

MOYANO, E. (2005): Capital social y desarrollo de zonas rurales. Documento de Trabajo, $\mathrm{n}^{\mathrm{o}} 13$, Instituto de Estudios Sociales de Andalucía (IESA-CSIC).

ORTEGA, J. (1998): «El patrimonio territorial: El territorio como recurso cultural y económico. Ciudades, n'. 4, 33-48.

PÉREZ, M. y LÓPEZ, F. (2005): «La contribución del turismo a la diversificación de actividades en un espacio rural periférico: análisis del impacto de la Iniciativa LEADER en Galicia». Revista Española Estudios Agrosociales y Pesqueros, nº 206, 111-136.

PLAZA, J. I. y HORTELANO, L. (2005): «Propuestas institucionales para fomentar el turismo en espacios naturales protegidos: Valoración del «Programa Parques Naturales en Castilla y León» y su incidencia en la Montaña Palentina». Publicaciones Tello Téllez de Meneses, $\mathrm{n}^{\circ}$ 76, 477-498.

PULIDO, J. (2007): «Los parques naturales como productos turísticos. Estudio de casos», en Ofertas no turismo rural: elaboración e promoción. (Pardellas, X. Coord.), Universidad de Vigo, 51-78.

RODRÍGUEZ, J., LÓPEZ, T. y SÁNCHEZ, S. (2010): «Análisis del desarrollo del enoturismo en España. Un estudio de caso». Cultur, Revista de Cultura e Turismo, año 4, nº 2 , 51-68.

SANZ, G. (2006): «Turismo en espacios protegidos: el Parque de las hoces del Río Duratón (Segovia)» en Turismo y cambio territorial: ¿eclosión, aceleración, desbordamiento? Universidad de Zaragoza, 291-302.

TANARRO, L.M. y MUÑOZ, J. (2010): «La evolución geomorfológica de las Hoces del Duratón en el macizo calcáreo de Sepúlveda». Cuaternario y Geomorfología, vol. 24, nº $1-2,113-134$.

TROITIÑO, M., DE MARCOS, J., GRACÍA M., DEL RÍO, I., CARPIO, J., DE LA CALLE, M. y ABAD, L.D. (2005): «Los espacios protegidos en España: significación e incidencia territorial». Boletín Asociación de Geógrafos Españoles, n 39, 227-265.

URRY, J. (2002): «Mobility and Proximity». Sociology, n 36, 255-274.

VARELA, C. y MARTÍN, F. (2011): «Problemas de sostenibilidad del turismo rural en España». Anales Geografía de la Universidad Complutense, vol. 31, n 1, 171-194.

VERA, F. et al. (1997): Análisis territorial del turismo. Barcelona, Ed. Ariel Geografía. 